\title{
A randomized, double-blind, placebo-controlled study evaluating the effects of the GOLO weight management program with and without Release supplement on weight and metabolic parameters in subjects with obesity
}

\author{
Robert J Buynak* \\ Buynak Clinical Research, Valparaiso, USA
}

\begin{abstract}
Objective: To determine the effects of the GOLO weight management program with Release supplement versus placebo on weight and metabolic parameters in subjects with obesity.

Methods: Sixty-eight (68) subjects with obesity were randomized in a double-blind, placebo-controlled study of the GOLO weight management program with Release supplement versus placebo at a single clinical site. Subjects were obese (average BMI $38.82 \mathrm{~kg} / \mathrm{m}^{2}$, SD 6.15) with evidence of insulin resistance at baseline (average HOMA-IR 3.06, SD 1.9, normal 0.5-1.9). The primary endpoint was the change in weight at end of the 13-week treatment period. Secondary endpoints included changes in body measurements, vital signs and laboratory measurements of obesity and metabolic syndrome at the end of treatment.

Results: Subjects allocated to the GOLO weight management program with Release supplement lost statistically significant more weight [-6.07 kg (SD 4.63)] than the subjects allocated to placebo $[-3.38 \mathrm{~kg}(2.81)](\mathrm{p}=0.047)$. Subjects receiving Release supplement also demonstrated a statistically significant greater reduction in waist circumference than those on placebo [placebo $-2.37 \mathrm{~cm}(5.12)$; treatment $-7.26 \mathrm{~cm}(6.43) ; \mathrm{p}=0.019$ ]. In addition, subjects allocated to Release supplement demonstrated significantly lower triglyceride levels compared to placebo [placebo $19.47 \mathrm{mg} / \mathrm{dl}$ (28.04); treatment $-35.21 \mathrm{mg} / \mathrm{dl}$ (43.29); p < 0.001]. Markers of insulin resistance also demonstrated significant improvements in subjects allocated to Release supplement as compared to placebo, including reductions in fasting insulin levels [placebo $1.03 \mathrm{mIU} / \mathrm{ml}$ (6.17); treatment -4.22 mIU/ml (5.42); $\mathrm{p}=0.022$ ] and HOMA-IR (placebo 0.42 (2.18); treatment -1.44 (2.04); $\mathrm{p}=.025$ ).
\end{abstract}

Conclusions: Treatment with the GOLO weight management program with Release supplement compared to placebo for 13-weeks resulted in statistically significant greater weight loss and improvement in metabolic parameters including insulin resistance in patients with obesity.

\section{Introduction}

Obesity is a common metabolic disorder in the United States and major risk factor for diabetes, cardiovascular disease and cancer $[1,2]$. To treat obesity, clinical guidelines recommend lifestyle modifications including reductions in daily caloric intake and increase in exercise as first line treatment [3]. Recommendations for second line treatment include pharmacotherapy or even bariatric surgery, but each comes with potential side effects and significant risk $[4,5]$.

People that are overweight and obese exhibit a heterogeneity in glucose metabolism, ranging from normal to insulin resistant to type 2 diabetes [6]. Elevated body weight and BMI are significant risk factors for the development of insulin resistance and type 2 diabetes mellitus [7]. People who are overweight and obese on this spectrum often have difficulty obtaining meaningful or sustained weight loss [8]. However, people with obesity who are insulin resistant or diabetic who lose weight generally improve glucose, insulin and lipid metabolism [9].

Commercial outpatient programs that encourage healthy dieting and exercise are commonly used by patients seeking weight loss in the US [10]. However, long term success of these programs can vary and has been lightly studied by the medical community $[10,11]$. In addition, over-the-counter supplements are often used by patients with obesity, although clinical study data supporting their use is often inconclusive or lacking $[12,13]$.

The GOLO Weight Management Program (GWMP) is a commercially available program that includes a diet and exercise plan in addition to a supplement known as Release (www.golo.com). The GWMP is designed to help people who are overweight or obese obtain a balance of nutrients from conventional foods, eat defined portioned meals leading to gradual weight loss and participate in a low-moderate level of daily exercise. The GWMP diet is a point-based system that includes foods from all four of the macronutrient food groups. Daily total caloric intake is based on the individual's sex, age, weight size and activity level. Additionally, the program includes printed instructions, motivation and tips supporting compliance and recommends a minimum of 15 minutes of exercise per day.

${ }^{\star}$ Correspondence to: Robert J Buynak, Buynak Clinical Research, Valparaiso, 55 University Suite 106, Valparaiso, USA, Tel: 219-464-8302, E-mail: rbuynak@ att.net

Key words: GOLO, weight management, obesity

Received: May 14, 2019; Accepted: May 24, 2019; Published: May 27, 2019 
Buynak RJ (2019) A randomized, double-blind, placebo-controlled study evaluating the effects of the GOLO weight management program with and without release supplement on weight and metabolic parameters in subjects with obesity

The Release supplement contains 7 plant-based ingredients and 3 minerals (Figure 1). Scientific evidence suggests that chromium, zinc and Banaba leaf extract supplements may have positive effects on glycemic control, lipid metabolism and healthy weight management [14-16].

Banaba leaf (Lagerstromia speciose) is a traditional medicine from southeast Asia which has shown hypoglycemic effects through unknown mechanisms [16-18]. Zinc is an essential trace mineral that plays an important role in normal islet function and is used in the production of insulin. One mechanism by which zinc may work to control glucose is through supporting insulin signal transduction, which may not function optimally in those with increased visceral fat [15]. Chromium has been shown to be an important cofactor in the action of insulin [19]. These agents are included in many supplements sold to people with obesity and diabetes. However, more rigorous studies of the effects of nutritional supplements on these conditions are needed, and this serves as an impetus for the current study.

In unpublished case studies of clinical and wellness program use in South Africa and the US, GWMP with Release supplement was shown to reduce body weight in both healthy and diabetic people who were overweight or obese [20]. Secondary endpoints including measures of blood sugar control and lipid metabolism were observed to improve in subjects participating in the study [20].

An open-label pilot study evaluating the effect of the GWMP with Release supplement on weight and indicators of glycemic control in subjects with stable type 2 diabetes mellitus and obesity was conducted at our site in 2017 [21]. This study demonstrated weight loss of $-3.3 \mathrm{~kg}$ (SD 2.47; $p<0.001$ ) which represented an average of -3.53\% (SD 0.02) weight loss and was statistically significant over a 13-week treatment period. In addition, reductions in Hemoglobin A1C averaged $-0.61 \%$ $(0.86 ; p=0.01)$ and reductions in HOMA-IR, a measure of insulin resistance, averaged $-2.25(3.33 ; p=0.02)$ which were both statistically

\section{Supplement Facts}

Serving Size: 1 Capsule Servings Per Container: 90

\begin{tabular}{|c|c|c|}
\hline Amount Per Serving & $\%$ Daily & Value \\
\hline Magnesium (as Albion ${ }^{\circledR}$ dimagnesium malate) & $15 \mathrm{mg}$ & $4 \%$ \\
\hline Zinc (as TRAACS ${ }^{\circledR}$ zinc bisglycinate chelate) & $10 \mathrm{mg}$ & $67 \%$ \\
\hline Chromium (as TRAACS ${ }^{\circledR}$ chromium nicotinate glycinate chelate) & $70 \mathrm{mcg}$ & $58 \%$ \\
\hline Proprietary Blend & $297 \mathrm{mg}$ & \\
\hline $\begin{array}{l}\text { Rhodiola (Rhodiola rosea) root extract (RhodioLife }{ }^{\circledR} \text { ) } \\
\text { [standardized to 3\% rosavins and } 1 \% \text { salidrosides] }\end{array}$ & & ** \\
\hline Inositol & & ** \\
\hline $\begin{array}{l}\text { Berberine } \mathrm{HCl} \text { [from standardized Barberry (Berberis vulgaris) } \\
\text { bark and root extract] }\end{array}$ & & ** \\
\hline Gardenia (Gardenia jasminoides) fruit extract 10:1 & & *** \\
\hline $\begin{array}{l}\text { Banaba (Lagerstroemia speciosa) leaf extract } \\
\text { [standardized to } 18 \% \text { corosolic acid] }\end{array}$ & & ** \\
\hline Salacia (Salacia reticulata) bark extract 6:1 (Salaretin ${ }^{\circledR}$ ) & & ** \\
\hline Apple (Malus domestica) fruit extract [standardized to $75 \%$ pol & olyphenols] & $* *$ \\
\hline${ }^{* *}$ Daily Value & & \\
\hline
\end{tabular}

Other ingredients: vegetable cellulose (capsule), tapioca dextrin, organic rice concentrate, silica.

This product does not contain soy, gluten, dairy, eggs, fish, shellfish, tree nuts, peanuts or wheat.

Figure 1. GOLO Release supplement package insert significant. These findings served as a scientific basis for a larger randomized placebo study.

While the GWMP has been developed and used in both healthy people and people with type 2 diabetes, more research is needed to determine to what extent the program and supplement support healthy weight loss. In addition, the component of weight loss and metabolic improvement contributed to by Release supplement is not known. This randomized, double-blind placebo-controlled study was intended to measure the effects of the GWMP with Release supplement versus GWMP with placebo supplement in a representative group of obese subjects with or without diabetes at one outpatient medical practice.

\section{Methods}

In this randomized, double-blind placebo-controlled study we randomized obese subjects with ages between 18 to 80 years and BMI between 30 and $60 \mathrm{~kg} / \mathrm{m}^{2}$ to the GWMP with either Release supplement or placebo. The study was conducted from July 2018 until December 2018. The site Buynak Clinical Research in Valparaiso, IN recruited subjects from the practice's patient population or through social media advertisement.

Subjects with and without type 2 diabetes were included, but those with type 1 diabetes or on insulin treatment were excluded. Other exclusion criteria included history of surgical treatments for weight loss or any unstable medical condition. All subjects provided informed consent in the form of a written consent form. The study was approved by Western Institutional Review Board. The study consisted of 8 visits over approximately 13 weeks.

At visit 1 , study eligibility was determined, and subjects were given the commercially available GOLO Weight Management Program and instructed on the program's diet and exercise guidelines. Subjects were randomized in a 1:1 fashion to receive either the Release supplement or matching placebo and instructed to take one capsule three times a day with meals. Subjects and study staff were blinded to the treatment allocation, and Release supplement and matching placebo capsules were supplied in blinded containers. Placebo capsule contained maltodextrin. At each in-office visit, unused Release supplement tablets and placebo were collected, compliance was calculated by pill counting, and open labeled 90-count Release supplement bottles were dispensed as needed.

Laboratory and body measurements were obtained as outlined below. Visit 2 consisted of a telephone call to subjects to assess tolerability of the program. At approximately 2 -week intervals, subjects returned for an office visit for compliance and tolerability assessment and body measurements. The final visit 8 occurred at approximately week 13 and included body measurements, laboratory analysis and compliance and tolerability assessment.

Body measurements were completed at in-office visits 1, 3 and 4 and included fasting weight, height, waist and hip circumference, and resting blood pressure and pulse. A Tanita bioimpedance scale (MC$780 \mathrm{U}$ ) was used to measure weight and calculate BMI, body fat and visceral fat. Laboratory evaluations were completed at Visit 1 and Visit 8 which included hemoglobin $\mathrm{A} 1 \mathrm{C}$, fasting insulin, fasting blood glucose and lipid panel (total cholesterol, LDL, HDL, triglycerides). A metabolic panel was also completed at Visit 1 and Visit 8 that included sodium, potassium, chloride, BUN, creatinine, calcium, total protein, albumin, alkaline phosphate, AST, ALT and carbon dioxide. Homeostatic model assessment of insulin resistance HOMA-IR was calculated using the formula [fasting blood glucose $(\mathrm{mg} / \mathrm{dl}) \times$ fasting insulin $(\mathrm{uIU} / \mathrm{ml}) / 405$ ] 
Buynak RJ (2019) A randomized, double-blind, placebo-controlled study evaluating the effects of the GOLO weight management program with and without release supplement on weight and metabolic parameters in subjects with obesity

[22] and was completed for subjects at the beginning and end of the 13 -week treatment period.

The primary endpoint for the study was change in weight at the end of approximately 13 weeks of treatment with GWMP with Release supplement versus GWMP with placebo. Secondary endpoints included differences in body measurements and body composition analysis, vital signs, A1C, fasting blood glucose, fasting insulin levels and HOMA-IR at the end of 13 weeks of treatment between the two treatment groups. Additional secondary endpoints included changes in lipid panel and metabolic panel results at the end of the study between the groups. Additional safety evaluations included the tracking of adverse events throughout the study period.

Differences between the treatment and control groups were analyzed using two-tailed t-tests assuming unequal variances at a significance level of 0.05 . These tests were used to compare the change of each group over the 13-week trial and to assess randomization of the subjects.

\section{GOLO weight management program}

At visit 1 subjects were educated on the GWMP diet and exercise plan and were given the same supplemental information given to GOLO commercial customers. Subjects were instructed to select at least one serving from each of 4 food groups (protein, vegetables, carbohydrates and fats) at each of the three meals. Protein or proteincarbohydrate snacks were permitted within the subject's daily calorie allotment. Examples of possible serving choices were outlined in the GOLO literature.

The total amount of food that the subject consumed per day was based on the subject's basal metabolic rate and exercise activity. Basal metabolic rates were derived at enrollment through a predetermined conversion based on sex, age, waist size and activity level. Subjects were instructed to add additional calorie allowances based on additional exercise as outlined in the GOLO literature. Daily calorie goals represented an approximately 500 calorie reduction from baseline maintenance levels. Compliance to diet was tracked through subject daily food diaries and subjects' calorie calculations that were later verified by study staff. Exercise was tracked in 15-minute increments in a subject diary.

\section{Results}

Sixty-eight subjects were consented and randomized into the study. Average baseline characteristics of the subjects are contained in table 1 . The average baseline weight was $106.97 \mathrm{~kg}$ (SD 16.64) and the average BMI was $38.82 \mathrm{~kg} / \mathrm{m}^{2}$ (6.15) which is considered obese.

Among the initial study population, average hemoglobin A1C (5.72\%, SD 0.84), fasting blood glucose (104.8 mg/dl, SD 27.9), LDL cholesterol (105.24 mg/dl, SD 22.85) and initial resting blood pressure (124.99 mmHg/79.34 mmHg, SD 13.37/10.03) were slightly elevated. This reflected the mixed nature of the group which contained both diabetic subjects and non-diabetic subjects and the heterogeneity of pre-treatment with anti-diabetic, blood pressure and cholesterol medications. While the average fasting insulin level $[11.4 \mathrm{uIU} / \mathrm{ml}$ (5.910; normal 1.9-23.0 uIU/ml] was within normal limits the average HOMA-IR [3.06 (1.90), normal 0.5-1.9] indicated the presence of insulin resistance in this subject population.

Table 2 describes the comparison of baseline characteristics between the placebo and treatment groups. Generally, baseline differences were
Table 1. Baseline characteristics of study participants

\begin{tabular}{|l|c|c|}
\hline Measure & Mean & Standard of Deviation \\
\hline Weight $(\mathrm{kg})$ & 106.97 & 16.64 \\
\hline Height $(\mathrm{cm})$ & 165.90 & 7.74 \\
\hline Body Fat $(\%)$ & 0.41 & 0.06 \\
\hline Body Fat $(\mathrm{kg})$ & 44.67 & 11.97 \\
\hline Muscle $(\mathrm{kg})$ & 58.27 & 11.91 \\
\hline Muscle (\%) & 0.54 & 0.11 \\
\hline BMI (kg/m2) & 38.82 & 6.15 \\
\hline Visceral Fat (kg) & 13.16 & 4.04 \\
\hline Waist (cm) & 118.15 & 14.84 \\
\hline Hips (cm) & 127.33 & 13.39 \\
\hline Waist/Hips & 0.93 & 0.07 \\
\hline Waist/Height & 0.71 & 0.09 \\
\hline BP Systolic (mmHg) & 124.99 & 13.37 \\
\hline BP Diastolic (mmHg) & 79.34 & 10.03 \\
\hline Pulse (bpm) & 71.26 & 11.37 \\
\hline Total Cholesterol (mg/dl) & 184.32 & 40.69 \\
\hline LDL (mg/dl) & 108.68 & 36.42 \\
\hline HDL (mg/dl) & 50.02 & 12.58 \\
\hline Triglycerides (mg/dl) & 126.72 & 66.59 \\
\hline A1C (\%) & 5.72 & 0.84 \\
\hline Insulin (mIU/l) & 11.40 & 5.91 \\
\hline Glucose (mg/dl) & 105.24 & 22.85 \\
\hline HOMA-IR & 3.06 & 1.90 \\
\hline & & \\
\hline
\end{tabular}

minor and not statistically significant. However, baseline diastolic blood pressure and pulse were higher in the treatment group at baseline than the placebo group, a difference that reached statistical significance.

34 subjects completed the approximately 13 -week study period. Of those subjects, 16 subjects randomized to placebo (Group A) and 18 subjects randomized to Release supplement (Group B). Of that total, 5 subjects had been previously diagnosed with type 2 diabetes and were on oral anti-diabetic therapy. Of the 68 subjects screened, 20 subjects self-terminated early for personal reasons (lack of time to participate, travel, personal emergencies), 11 subjects were removed early for poor compliance with diet or pill counts and 3 subjects withdrew for adverse events (2 loose stool, 1 nausea).

Changes from baseline week 1 to week 13 in weight, BMI, body analysis and body measurements for each group are listed in table 3. In terms of the primary endpoint, subjects randomized to the Release supplement lost statistically significant more weight than those assigned to placebo [placebo $-3.38 \mathrm{~kg}$ (2.81); treatment $-6.07 \mathrm{~kg}$ (4.63); $p=$ 0.047 ]. This represented a $-3 \%$ change in weight ( $95 \% \mathrm{CI}:-2$ to -5$)$ in the placebo group compared to a $-6 \%$ change in weight ( $95 \% \mathrm{CI}$ " -3 to -8 ) in the treatment group. In addition, reductions in waist circumference [placebo $-2.37 \mathrm{~cm}$ (5.12); treatment $-7.26 \mathrm{~cm}(6.43) ; p=0.019$ ] and waist/height ratio [placebo $-0.01(0.03)$; treatment $-0.04(0.04) ; p=$ 0.026] were also statistically significant for the Release-treated group compared to placebo. In terms of vital signs, subjects randomized to the Release supplement showed statistically significant greater reductions in diastolic BP [placebo $1.31 \mathrm{mmHg}(7.38)$; treatment $-4.11 \mathrm{mmHg}$ (6.62); $p=0.032$ ] and pulse [placebo $4.38 \mathrm{bpm}$ (10.44); treatment -3.44 bpm (4.83); $p=0.012]$.

Changes from baseline week 1 to week 13 in markers of glycemic control and insulin sensitivity are listed in table 4. Levels of fasting blood glucose [placebo $0.73 \mathrm{mg} / \mathrm{dl}$ (10.71); treatment $-10.71 \mathrm{mg}$ / dl (28.61); $p=0.178$ ] and hemoglobin A1C [placebo 0.02\% (0.18); treatment $-0.18(0.53) ; p=0.202$ ] demonstrated a trend towards larger 
Buynak RJ (2019) A randomized, double-blind, placebo-controlled study evaluating the effects of the GOLO weight management program with and without release supplement on weight and metabolic parameters in subjects with obesity

Table 2. Baseline comparison of placebo group to treatment group, as mean (SD)

\begin{tabular}{|c|c|c|c|c|}
\hline Measure & Placebo Baseline (SD) Group A & Treatment Baseline (SD) Group B & Average Difference (T - P) & $\begin{array}{c}P \\
\text { Value }\end{array}$ \\
\hline Weight (kg) & $107.21(20.95)$ & $106.71(16.64)$ & -0.51 & 0.91 \\
\hline Height $(\mathrm{cm})$ & $164.32(6.28)$ & $167.57(8.82)$ & 3.26 & 0.09 \\
\hline Body Fat (\%) & $0.43(0.05)$ & $0.4(0.07)$ & -0.02 & 0.11 \\
\hline Body Fat (kg) & $46.17(12.63)$ & $43.13(11.22)$ & -3.04 & 0.17 \\
\hline Muscle (kg) & $56.31(13.24)$ & $60.28(10.18)$ & 3.97 & 0.17 \\
\hline Muscle (\%) & $0.53(0.1)$ & $0.55(0.12)$ & 0.02 & 0.55 \\
\hline BMI $\left(\mathrm{kg} / \mathrm{m}^{2}\right)$ & $39.55(6.55)$ & $38.04(5.68)$ & -1.52 & 0.31 \\
\hline Visceral Fat (kg) & $13.71(4.25)$ & $12.61(3.8)$ & -1.10 & 0.27 \\
\hline Waist (cm) & $119.34(15.75)$ & $116.89(13.95)$ & -2.44 & 0.50 \\
\hline Hips $(\mathrm{cm})$ & $128.48(13.44)$ & $126.11(13.44)$ & -2.37 & 0.47 \\
\hline Waist/Hips & $0.93(0.06)$ & $0.93(0.08)$ & 0.00 & 0.98 \\
\hline Waist/Height & $0.73(0.09)$ & $0.7(0.09)$ & -0.03 & 0.21 \\
\hline BP Systolic (mmHg) & $123.2(13.41)$ & $126.88(13.26)$ & 3.68 & 0.26 \\
\hline BP Diastolic (mmHg) & $76.66(9.42)$ & $82.18(10.01)$ & 5.52 & 0.02 \\
\hline Pulse (bpm) & $68.26(10.92)$ & $74.45(1.12)$ & 6.20 & 0.02 \\
\hline Total Cholesterol (mg/dl) & $188.54(41.5)$ & $179.55(39.9)$ & -8.99 & 0.37 \\
\hline LDL (mg/dl) & $112.97(38.12)$ & $103.84(34.37)$ & -9.13 & 0.31 \\
\hline HDL (mg/dl) & $50.71(11.26)$ & $49.23(14.07)$ & -1.49 & 0.64 \\
\hline Triglycerides (mg/dl) & $122.74(58.05)$ & $131.1(75.59)$ & 8.36 & 0.62 \\
\hline $\mathrm{A} 1 \mathrm{C}(\%)$ & $5.66(0.64)$ & $5.78(1.02)$ & 0.12 & 0.57 \\
\hline Insulin (mIU/L) & $11.58(6.64)$ & $11.19(5.06)$ & -0.39 & 0.79 \\
\hline Glucose (mg/dl) & $103.4(19.68)$ & $107.32(26.16)$ & 3.92 & 0.50 \\
\hline HOMA-IR & $3.03(1.9)$ & $3.09(1.93)$ & 0.07 & 0.88 \\
\hline
\end{tabular}

Table 3. Changes in weight and body measurements, as mean (SD)

\begin{tabular}{|c|c|c|c|c|c|c|c|}
\hline Measure & Placebo Visit 1 & Placebo Visit 13 & Placebo Change & Treatment Visit 1 & Treatment Visit 13 & Treatment Change & $\begin{array}{c}P \\
\text { Value }\end{array}$ \\
\hline Weight (kg) & $97.14(18.49)$ & $93.76(17.46)$ & $-3.38(2.81)$ & $109.19(15.08)$ & $103.12(14.8)$ & $-6.07(4.63)$ & 0.047 \\
\hline BMI $\left(\mathrm{kg} / \mathrm{m}^{2}\right)$ & $37.12(6.15)$ & $35.76(5.98)$ & $-1.36(1.09)$ & $37.84(6.04)$ & $35.73(5.88)$ & $-2.11(1.57)$ & 0.114 \\
\hline Waist $(\mathrm{cm})$ & $112.1(12.2)$ & $109.73(11.92)$ & $-2.37(5.12)$ & $117.26(13.7)$ & $110(13.65)$ & $-7.26(6.43)$ & 0.019 \\
\hline Hips (cm) & $122.89(13.91)$ & $120.36(13.22)$ & $-2.53(4.7)$ & $127.22(14.67)$ & $121.96(13.31)$ & $-5.26(5.24)$ & 0.120 \\
\hline Waist/Height & $0.69(0.07)$ & $0.68(0.07)$ & $-0.01(0.03)$ & $0.69(0.09)$ & $0.65(0.09)$ & $-0.04(0.04)$ & 0.026 \\
\hline Waist/Hips & $0.91(0.06)$ & $0.91(0.06)$ & $00(0.04)$ & $0.92(0.08)$ & $0.9(0.1)$ & $-0.02(0.03)$ & 0.147 \\
\hline Fat $(\mathrm{kg})$ & $40.61(11.1)$ & $38.63(10.27)$ & $-1.98(2.34)$ & $42.51(11.56)$ & $39.29(10.89)$ & $-3.22(4.47)$ & 0.318 \\
\hline Fat $(\%)$ & $0.41(0.05)$ & $0.41(0.05)$ & $-0.01(0.02)$ & $0.39(0.08)$ & $0.38(0.07)$ & $-0.01(0.03)$ & 0.721 \\
\hline Systolic BP (mmHG) & $125.38(16.38)$ & $129.56(14.22)$ & $4.19(12.32)$ & $127.28(14.27)$ & $127.44(20.21)$ & $0.17(13.64)$ & 0.373 \\
\hline $\begin{array}{l}\text { Diastolic BP } \\
\text { (mmHG) }\end{array}$ & $76.19(7.3)$ & $77.5(10.24)$ & $1.31(7.38)$ & $82.94(10.3)$ & $78.83(8.52)$ & $-4.11(6.62)$ & 0.032 \\
\hline Pulse (bpm) & $65.94(8.08)$ & $70.31(12.24)$ & $4.38(10.44)$ & $74.89(11.48)$ & $71.44(11.82)$ & $-3.44(4.83)$ & 0.012 \\
\hline
\end{tabular}

Table 4. Changes in markers of glycemic control and insulin resistance, as mean (SD)

\begin{tabular}{|c|c|c|c|c|c|c|c|}
\hline Measure & Placebo Visit 1 & Placebo Visit 13 & Placebo Change & Treatment Visit 1 & Treatment Visit 13 & Treatment Change & $\begin{array}{c}P \\
\text { Value }\end{array}$ \\
\hline Glucose (mg/dL) & $94.87(10.23)$ & $95.6(10.4)$ & $0.73(10.71)$ & $115.43(36.47)$ & $104.71(27.21)$ & $-10.71(28.61)$ & 0.178 \\
\hline $\mathrm{A} 1 \mathrm{C}(\%)$ & $5.43(0.41)$ & $5.45(0.32)$ & $0.02(0.18)$ & $6.3(1.28)$ & $6.12(0.98)$ & $-0.18(0.53)$ & 0.202 \\
\hline Insulin (uIU/mL) & $9.63(6.05)$ & $10.66(10.34)$ & $1.03(6.17)$ & $14.26(5.16)$ & $10.04(4.34)$ & $-4.22(5.42)$ & 0.022 \\
\hline HOMA-IR & $2.26(1.4)$ & $2.68(3.18)$ & $0.42(2.18)$ & $4.21(2.25)$ & $2.77(1.93)$ & $-1.44(2.04)$ & 0.025 \\
\hline
\end{tabular}

reductions in subjects randomized to the Release supplement compared to placebo but were not statistically significant. However, markers of insulin resistance improved significantly in the Release-treated group, with insulin levels decreasing more in the treatment group than in the placebo group [placebo $1.03 \mathrm{mIU} / \mathrm{l}$ (6.17); treatment $-4.22 \mathrm{mIU} / \mathrm{l}$ (5.42) $p=0.022]$. HOMA-IR, a standard calculation of insulin resistance, dropped even more extensively in the Release-treated group with an average reduction of $-27 \%$ (95\% CI: -47 to -8$)$ compared to an average increase of $16 \%$ in the placebo group (95\%CI: -13 to 46$)(p$ $=0.014)$.
Reductions from baseline week 1 to week 13 in total cholesterol [placebo 1.93 (29.95); treatment -8.29 (17.36); $p=.269$ ] and LDL cholesterol [placebo 1.4 (25.73); treatment -2.14 (13.18); $p=0.642$ ] demonstrated a trend towards larger reductions in subjects randomized to the Release supplement compared to placebo but were not statistically significant. However, statistically significant larger improvements in triglyceride levels [placebo $19.47 \mathrm{mg} / \mathrm{dl}$ (28.04); treatment $-35.21 \mathrm{mg}$ / $\mathrm{dl}$ (43.29); $p<0.001$ ] were seen in subjects randomized to the Releasetreated group compared to placebo. Changes in liver enzymes and kidney functions were not different between the two groups (Table 5). 
Buynak RJ (2019) A randomized, double-blind, placebo-controlled study evaluating the effects of the GOLO weight management program with and without release supplement on weight and metabolic parameters in subjects with obesity

Table 5. Changes in lipid panel, transaminases, and renal testing, as mean (SD)

\begin{tabular}{|c|c|c|c|c|c|c|c|}
\hline Measure & Placebo Visit 1 & Placebo Visit 13 & Placebo Change & Treatment Visit 1 & Treatment Visit 13 & Treatment Change & $\begin{array}{c}P \\
\text { Value }\end{array}$ \\
\hline $\begin{array}{l}\text { Total Cholesterol } \\
(\mathrm{mg} / \mathrm{dL})\end{array}$ & $189.6(46.78)$ & $191.53(44.39)$ & $1.93(29.95)$ & $174.71(43.17)$ & $166.43(43.28)$ & $-8.29(17.36)$ & 0.269 \\
\hline $\mathrm{LDL}(\mathrm{mg} / \mathrm{dL})$ & $115.07(46.29)$ & $116.47(42.61)$ & $1.4(25.73)$ & $98.36(31.13)$ & $96.21(31.38)$ & $-2.14(13.18)$ & 0.642 \\
\hline $\mathrm{HDL}(\mathrm{mg} / \mathrm{dL})$ & $54.2(13.27)$ & $53.73(12.01)$ & $-0.47(6.14)$ & $43.43(9.88)$ & $43.71(10.24)$ & $0.29(3.47)$ & 0.686 \\
\hline Triglycerides (mg/dL) & $102.13(43.55)$ & $121.6(65.78)$ & $19.47(28.04)$ & $163.93(95.24)$ & $128.71(64.93)$ & $-35.21(43.29)$ & $<0.001$ \\
\hline $\operatorname{AST}(\mathrm{u} / \mathrm{L})$ & $21.8(7.89)$ & $19.07(6.37)$ & $-2.73(4.88)$ & $19.21(7.22)$ & $18.29(6.47)$ & $-0.93(4.12)$ & 0.290 \\
\hline $\operatorname{ALT}(\mathrm{u} / \mathrm{L})$ & $23.27(14.31)$ & $18.27(9.84)$ & $-5(8.6)$ & $20.57(10.49)$ & $19.64(10.04)$ & $-0.93(4.14)$ & 0.116 \\
\hline Creatinine (mg/dL) & $0.81(0.14)$ & $0.8(0.11)$ & $-0.01(0.05)$ & $0.79(0.13)$ & $0.82(0.13)$ & $0.03(0.1)$ & 0.175 \\
\hline BUN (mg/dL) & $15(3.98)$ & $15.4(3.31)$ & $0.4(4.03)$ & $12.36(4.22)$ & $12.5(4.74)$ & $0.14(2.14)$ & 0.831 \\
\hline
\end{tabular}

\section{Discussion}

This study demonstrated statistically significant improvements in several important body measurements and laboratory tests in subjects following the GWMP who were randomized to the Release supplement compared to placebo. Because all subjects followed a similar diet and exercise plan, these results suggest that the components of Release supplement may add significant health benefits to the GWMP.

Patients with obesity often to struggle to lose weight even when following proper diet and exercise program [8]. In this study, the GWMP alone produced weight loss in the control and treatment groups. However, the addition of Release supplement resulted in a statistically significant larger weight loss [placebo $-3.38 \mathrm{~kg}$ (2.81); treatment -6.07 $\mathrm{kg}$ (4.63); $p=0.047$ ] compared to placebo. By achieving this primary endpoint, this study indicates that the Release supplement could serve as a useful addition to diet and exercise programs for patients with type 2 diabetes.

In addition to weight loss, treatment programs that target additional risk factors for metabolic syndrome and cardiovascular disease like elevated blood pressure, central obesity and abnormal lipid metabolism are also needed to improve health in patients with obesity [1]. Each of these factors contribute additional cardiovascular risk in addition to that of diabetes and obesity alone [23]. The statistically significant improvements in waist circumference, diastolic BP and triglycerides levels demonstrated in subjects randomized to the Release supplement compared to placebo in this study indicate additional potential health benefits for participants following the GWMP. In addition to these statistically significant improvements, positive trends were seen in reductions of that were not statistically significant. Combined with weight loss, all of these additional benefits could substantially improve the cardiovascular risk profile in patients participating in the GWMP with Release supplement.

Improvements in markers of insulin resistance were the most notable results of the study and are consistent with results from the previous pilot study of the GWMP with Release supplement [21]. This study demonstrated a significant improvement in insulin resistance as measured by fasting insulin levels and HOMA-IR in the subjects treated with the GWMP with Release supplement for 13-weeks as compared to placebo supplement. Elevated levels of fasting insulin and HOMAIR are hallmarks of the metabolic syndrome and type 2 diabetes, and elevated HOMA-IR serves as another important independent risk factor for cardiovascular disease [24,25].

In the current study, reductions in HOMA-IR of -27 \% (95\% CI: -47 to -8 ) in subjects randomized to the Release supplement approximate that seen with even prescribed medications like pioglitazone or metformin [26]. In that comparable study, pioglitazone reduced HOMA-IR by $39 \%$ which was statically significant, while metformin reduced HOMA-IR by $25 \%$ and was not statistically significant [26]. Another study in a group of insulin resistant people demonstrated that pioglitazone reduced HOMA-IR by $-24 \%$ after a year of treatment (from $5.4 \pm 2.6$ to $4.1 \pm 2.8, p<0.0001$ ) which was statistically significant [27]

The components of the GWMP that are responsible for the improvement in HOMA-IR have not been clearly identified. Weight loss itself can lower HOMA-IR levels, although not to the extent seen in this study [28]. This study indicates the components of the Release supplement may play a role in reducing insulin resistance and are possibly additive to that achieved by diet alone.

The significant improvements in HOMA-IR demonstrated by the GWMP system with the Release supplement suggest a beneficial role in other disease states including the Metabolic Syndrome or PCOS. In these disorders, insulin resistance is generally a major component, and treatment of the insulin resistance improves clinical outcomes $[29,30]$. More studies are needed of the GWMP with Release in these individual areas of interest.

The study was limited by selection of subjects at only one clinical site. Baseline differences between groups, especially those that were statistically significant, could have confounded the magnitude of results. The large number of dropouts could also have confounded the results. As in any diet study, subject compliance with diet and exercise was difficult to measure and poor subject compliance with the GWMP diet, based on food logs, or exercise component may also have influenced the results of the study. Although compliance with the Release supplement as obtained by pill counts ( 95 percent overall compliance by pill count) was excellent, compliance with diet and exercise recommendations was self-reported, variable and more difficult to quantify.

\section{Conclusion}

Treatment with the GOLO Weight Management Program with Release supplement compared to placebo for 13-weeks resulted in statistically significant greater weight loss and improvement in metabolic parameters including insulin resistance in patients with obesity.

\section{Acknowledgements}

The author thanks Jacob Hoffman, BS/BA for statistical analysis.

\section{Conflict of interest}

The author receives funding from GOLO, LLC per a research and consulting agreement. 
Buynak RJ (2019) A randomized, double-blind, placebo-controlled study evaluating the effects of the GOLO weight management program with and without release supplement on weight and metabolic parameters in subjects with obesity

\section{Data sharing plan}

All the individual data collected during the trial will be available, after declassification, in addition to the study protocol, informed consent form and clinical study report immediately following the publication, ending in 36 months, to researchers who provide a methodologically sounds proposal to achieve aims in the approved proposal. Proposals should be directed to rbuynak@att.net. Data are available only in hard copy format.

\section{References}

1. American Medical Association House of Delegates. Recognition of obesity as a disease. Resolution 420 (A-13). Available from: http://www.npr.org/documents/2013/ jun/ama-resolution-obesity.pdf.

2. Klein S, Burke LE, Bray GA, Blair S, Allison DB, et al. (2004) Clinical implications of obesity with specific focus on cardiovascular disease: A statement for professionals from the American Heart Association Council on Nutrition, Physical Activity, and Metabolism: endorsed by the American College of Cardiology Foundation. Circulation 110: 2952-2967. [Crossref]

3. Garvey WT, Mechanick JI, Brett EM, Garber AJ, Hurley DL, et al. (2016) Reviewers of the AACE/ACE Obesity Clinical Practice Guidelines. American Association of Clinical Endocrinologists and American College of Endocrinology comprehensive clinical practice guidelines for medical care of patients with obesity. Endocr Pract 22: 1-203. [Crossref]

4. Jensen MD, Ryan DH, Apovian CM, Ard JD, Comuzzie AG, et al. (2014) 2013 AHA/ ACC/TOS guideline for the management of overweight and obesity in adults: a report of the American College of Cardiology/American Heart Association Task Force on Practice Guidelines and The Obesity Society. Circulation 129: S102-S138. [Crossref]

5. Mechanick JI, Youdim A, Jones DB, Garvey WT, Hurley DL, et al. (2013) Clinical practice guidelines for the perioperative nutritional, metabolic, and nonsurgical support of the bariatric surgery patient-2013 update: cosponsored by American Association of Clinical Endocrinologists, the Obesity Society, and American Society for Metabolic \& Bariatric Surgery. Endocr Pract 19: 337-372. [Crossref]

6. Narayan KM, Boyle JP, Thompson TJ, Gregg EW, Williamson DF (2007) Effect of BMI on Lifetime Risk for Diabetes in the U.S. Diabetes Care 30: 1562-1566. [Crossref]

7. Gavin JR 3rd, Rodbard HW, Fox KM, Grandy S (2009) Association of overweight and obesity with health status, weight management, and exercise behaviors among individuals with type 2 diabetes mellitus or with cardiometabolic risk factors. Risk Manag Healthc Policy 2: 1-7. [Crossref]

8. Van Gaal L, Scheen A (2015) Weight Management in Type 2 Diabetes: Current and Emerging Approaches to Treatment. Diabetes Care 38: 1161-1172. [Crossref]

9. Standards of Medical Care in Diabetes-2017: Summary of Revisions. Diabetes Care 40: S4-S5. [Crossref]

10. Gudzune KA, Doshi RS, Mehta AK, Chaudhry ZW, Jacobs DK, et al. (2015) Efficacy of commercial weight-loss programs. An updated systematic review. Ann Intern Med 162: 501-512. [Crossref]

11. McEvedy SM, Sullivan-Mort G, McLean SA, Pascoe MC, Paxton SJ (2017) Ineffectiveness of commercial weight-loss programs for achieving modest but meaningful weight loss: systematic review and meta-analysis. J Health Psychol 22: 1614-1627. [Crossref]

12. Pittler MH, Ernst E (2004) Dietary supplements for body-weight reduction: a systematic review. Am J Clin Nutr 79: 529-536. [Crossref]

13. Ríos-Hoyo A, Gutiérrez-Salmeán G (2016) New Dietary Supplements for Obesity: What We Currently Know. Curr Obes Rep 5: 262. [Crossref]
14. Judy WV, Hari SP, Stogsdill WW, Judy JS, Naguib YM, et al. (2003) Antidiabetic activity of a standardized extract (Glucosol) from Lagerstroemia speciose leaves in Type 2 Diabetics. A dose-dependence study. J Ethnopharmacol 87: 115-117. [Crossref]

15. Jayawardena R, Ranasinghe $P$, Galappatthy $P$, Malkanthi R, Constantine $G$, et al (2012) Effects of zinc supplementation on diabetes mellitus: a systematic review and meta-analysis. Diabetol Metab Syndr 4: 13. [Crossref]

16. Miura T, Takagi S, Ishida T (2012) Management of Diabetes and Its Complications with Banaba (Lagerstroemia speciosa L.) and Corosolic Acid. Evid Based Complement Alternat Med 2012: 871495. [Crossref]

17. Tsuchibe S, Kataumi S, Mori M, Mori H (2006) An inhibitory effect on the increase in the postprandial blood glucose by Banaba extract capsule enriched corosolic acid. Journal for the Integrated Study of Dietary Habits 17: 255-259.

18. Judy WV, Hari SP, Stogsdill WW, Judy JS, Naguib YM, et al. (2003) Antidiabetic activity of a standardized extract (Glucosol ${ }^{\mathrm{TM}}$ ) from Lagerstroemia speciosa leaves in Type II diabetics: A dose-dependence study. J Ethnopharmacol 87: 115-117. [Crossref]

19. Cefalu WT, Hu FB (2004) Role of Chromium in Human Health and in Diabetes. Diabetes Care 27: 2741-2751. [Crossref]

20. Pilot Studies on the Efficacy of a Diet Program on Body Weight in Overweight and Obese South Africans. (Unpublished, available on GOLO website: https://www.golo. com/golo-studies)

21. Buynak RJ (The Effects of the GOLO Weight Management Program and Release Supplement on Weight and Glycemic Control in Patients with Type 2 Diabetes Mellitus and Obesity (Unpublished, available on GOLO website: https://www.golo.com/golostudies).

22. Bonora E, Kiechl S, Willeit J, Oberhollenzer F, Egger G, et al. (2007) Insulin resistance as estimated by homeostasis model assessment predicts incident symptomatic cardiovascular disease in Caucasian subjects from the general population: the Bruneck study. Diabetes Care 30: 318-324. [Crossref]

23. Alshehri AM (2010) Metabolic syndrome and cardiovascular risk. J Family Community Med 17: 73-78. [Crossref]

24. Mossmann M, Wainstein MV, Gonçalves SC, Wainstein RV, Gravina GL, et al. (2015) HOMA-IR is associated with significant angiographic coronary artery disease in nondiabetic, non-obese individuals: a cross-sectional study. Diabetol Metab Syndr 7: 100 [Crossref]

25. Bonora E, Formentini G, Calcaterra F, Lombardi S, Marini F, et al. (2002) HOMAEstimated Insulin Resistance Is an Independent Predictor of Cardiovascular Disease in Type 2 Diabetic Subjects. Diabetes Care 25: 1135-1141. [Crossref]

26. Eguchi K, Tomizawa H, Ishikawa J, Hoshide S, Numao T, et al. (2007) Comparison of the effects of pioglitazone and metformin on insulin resistance and hormonal markers in patients with impaired glucose tolerance and early diabetes. Hypertens Res 30: 2327. [Crossref]

27. Inzucchi SE, Viscoli CM, Young LH, Furie KL, Gorman M, et al. (2016) Pioglitazone Prevents Diabetes in Patients with Insulin Resistance and Cerebrovascular Disease. Diabetes Care 39: 1684-1692. [Crossref]

28. Clamp LD, Hume DJ, Lambert EV, Kroff J (2017) Enhanced insulin sensitivity in successful, long-term weight loss maintainers compared with matched controls with no weight loss history. Nutr Diabetes 7: e282. [Crossref]

29. Lankarani M, Valizadeh N, Heshmat R, Peimani M, Sohrabvand F (2009) Evaluation of insulin resistance and metabolic syndrome in patients with polycystic ovary syndrome. Gynecol Endocrinol 25: 504-507. [Crossref]

30. Caserta D, Adducchio G, Picchia S, Ralli E, Matteucci E, et al. (2014) Metabolic syndrome and polycystic ovary syndrome: an intriguing overlapping. Gynecol Endocrinol 30: 397-402. [Crossref]

Copyright: $\odot 2019$ Buynak RJ. This is an open-access article distributed under the terms of the Creative Commons Attribution License, which permits unrestricted use, distribution, and reproduction in any medium, provided the original author and source are credited. 